\title{
CACCIOPPOLI'S INEQUALITY FOR QUASILINEAR ELLIPTIC OPERATORS
}

\author{
IVAN PERIĆ AND DARKO ŽUBRINIĆ
}

Abstract. We generalize Caccioppoli's inequality to the setting of quasilinear operators of Leray - Lions type, including arbitrary open subsets in $\mathbf{R}^{N}, N \geqslant 1$, instead of balls, and we obtain an explicit value of the constant on the right-hand side. The best Caccioppoli constant for the $p$-Laplacian is $\leqslant p^{p}$.

Mathematics subject classification (1991): 35B99, 26D10.

Key words and phrases: quasilinear elliptic, Caccioppoli inequality, convex functions.

\section{REFERENCES}

[1] DAUTRAY R. \& LiONS J.-L., Analyse mathématique et calcul numerique por les sciences et les techniques, 2, L'Opérateur de Laplace, Masson, Paris, (1987).

[2] Giaquinta M., On differentiability of variational integrals, in Nonlinear Analysis, Function Spaces and Applications, Teubner, (1982).

[3] Giaquinta M., Multiple integrals in the calculus of variations and elliptic systems, Princeton University Press, Princeton, New Jersey, (1983).

[4] Gilbarg D., Trudinger N. S., Elliptic partial differential equations of second order, Springer-Verlag, Berlin, (1983).

[5] Heinonen J., KilpeläInEn T., MARTio O., Nonlinear potential theory of degenerate elliptic equations, Oxford University Press, Oxford, (1993).

[6] KENIG C. E., Harmonic analysis techniques for second order elliptic boundary value problems, CBMS, 83, American Mathematical Society, Rhode Island, 1994.

[7] KILPELÄINEn T., KosKela P., Global integrability of the gradients of solutions to partial differential equations, Nonlinear Analysis, Vol. 23, No. 7, 1994, 899-909

[8] KINDERLEHRER D., STAMPACCHIA G., An introduction to variational inequalities and their applications, Academic Press, 1980.

[9] Korkut L., PAŠIĆ M., ŽUbrinić D., Some qualitative properties of quasilinear elliptic equations and applications, submitted for publication,

[10] Mitrović D. \& ŽUbrinIĆ D., Fundamentals of applied functional analysis, Pitman Monographs and Surveys in Pure and Applied Mathematics 91, Addison Wesley Longman, 1998. 